\title{
Responsiveness of the Activity Participation Outcome Measure in adult patients with Traumatic Brain Injury in an acute private neurological rehabilitation setting in South Africa.
}

\author{
Alison Louise Camp, B.OT (UKZN), MSc OT (Wits). https://orcid.org/0000-000 I-6798-6204 \\ Occupational Therapist, Siza Rehabilitation Hillcrest Private Hospital; ORCID Number:
}

\section{Daleen Casteleijn, B OT(UP), B OT(Hons) (Medunsa), PG Dip Voc Rehab (UP), Dip Higher Education and} Training Practices (UP), M OT(UP), PhD (UP). https://orcid.org/0000-0002-06 I I-8662

Associate Professor, Department of Occupational Therapy, School of Therapeutic Sciences, University of the Witwatersrand

*Dineo Thupae, BSc OT (UWC), MPH (Wits). https://orcid.org/0000-000 I-6470- 1333

Lecturer, Department of Occupational Therapy, Dept of Occupational Therapy, School of Therapeutic Sciences, Faculty of Health Sciences, University of the Witwatersrand

Introduction: Acute neurological rehabilitation aims to reduce the burden of care of patients with traumatic brain injury (TBI) and increase their activity participation. Tracking change throughout the rehabilitation is essential for funders of the service as well as the patient. Valid, reliable and responsive outcome measures are thus needed for accurate measurement of change.

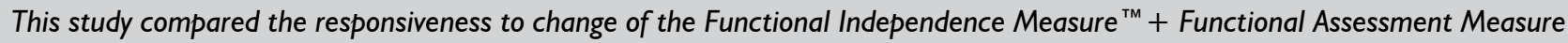
$\left(\right.$ FIM $^{\mathrm{TM}}+$ FAM) with the Activity Participation Outcomes Measure (APOM). This was administered TBI patients in the acute neurological rehabilitation phase in a private health care facility in South Africa.

Method: A quantitative, prospective, longitudinal cohort design was used. A sample of 24 in-patients over 12 months was scored weekly on both outcome measures. The responsiveness between the APOM and FIM ${ }^{\mathrm{TM}}+$ FAM was tested using the dependent $t$-test for paired samples and the effect size from admission to discharge was calculated with the standardised response mean.

Results: Both measures were responsive to change and tracked improvement in activity participation (APOM) and reduction of burden of care $\left(F I M^{\mathrm{TM}}+\right.$ FAM). No significant statistical difference was found between the responsiveness of the two measures however positive changes were reported in each individual patient.

Conclusion: Although both measures are responsive to track change in TBI patients, the APOM includes more specific items that occupational therapists address in rehabilitation. The lack of a measure of physical components in the APOM makes it a difficult to be the only one to use in an environment where there is a high physical burden of care in patients. However, the APOM could be used in conjunction with other impairment-based scales that target physical components. It is recommended that more occupational therapists use the APOM with TBI populations.

Key words: Activity participation outcome measure, Traumatic Brain Injuries, Acute neurological rehabilitation, responsiveness

\section{INTRODUCTION}

Traumatic Brain Injury (TBI) has been referred to as a silent epidemic by the American Centers for Disease Control and Prevention'. The impact of even a minor TBI can lead to lifelong difficulties for a person to continue being a productive and independent member of society. The result is that the person with the TBI finds it difficult to fit in socially, in the formal work sector and even maintain personal, intimate relationships with their family ${ }^{2}$. Family members often feel that they no longer have the person with them that they once had.

"If a man has lost a leg or an eye, he knows he has lost a leg or an eye; but if he has lost a self - himself - he cannot know it, because he is no longer there to know it"3:35. People with TBI experience a loss of the sense of self. This is seen in practice from the acute phase of recovery often to the end of the person's life ${ }^{4}$.
The challenge to occupational therapists is to identify the extent of the loss of oneself, address it in therapy and measure the progress of this abstract and latent variable as it is not physical or concrete.

Once the patient is medically stabilised following the onset of $\mathrm{TBI}$, there is a need for comprehensive rehabilitation. The work of the rehabilitation team is to facilitate independence in activities of daily living (ADLs) and instrumental activities of daily living (IADLs) and improve the quality of life of the affected person and those involved in that person's life ${ }^{4}$. However, one has to determine what constitutes good quality of life and how can it can be measured objectively during rehabilitation.

Rehabilitation, through the use of activities aims to improve the individual's function to the maximum level of ability possible within the limitations of deficits resulting from brain injury. It is therefore 
necessary to measure the effectiveness of rehabilitation to ascertain if aims were met. The assessment of outcome is how one can determine whether the rehabilitation aims have been achieved. Outcomes may be assessed at the levels of impairment, activity or participation. Activity measures are therefore important outcomes for cognitive rehabilitation as Quality of life is best assessed as component domains rather than a single measure.

A number of studies have shown that attaining independence in ADLs and IADLs, an active social support structure and a rewarding occupation are all contributors towards attaining a satisfactory quality of life post $\mathrm{TB}^{5-7}$. Early intervention has been shown to improve functional outcomes in persons with $\mathrm{TB}^{8}$. Intervention from a co-ordinated multidisciplinary team has been shown to be more effective than uncoordinated treatment ${ }^{9}$. However, all interventions are dependent on funding and cost effectiveness. Evidence of change needs to be demonstrated to ensure continued funding and effective services. This is done through the implementation of appropriate outcome measures.

In many private rehabilitation units in South Africa the Functional Independence Measure ${ }^{\mathrm{TM}}$ and Functional Assessment Measure $\left(\mathrm{FIM}^{\mathrm{TM}}+\mathrm{FAM}\right)^{10}$ are the outcome measure that are used on a weekly basis by any member of the multidisciplinary health team to indicate change in the independent functioning of patients to the team and funders.

Originally developed as the FIM ${ }^{\mathrm{TM}}$, it was found that it had a ceiling effect (maximum scores) that limited its usefulness in detecting subtle changes in improvement. The FAM was added as adjunct to the $\mathrm{FIM}^{\mathrm{TM}}$ in order to lessen the ceiling effect. Together they are known as the $\mathrm{FIM}^{\mathrm{TM}}+\mathrm{FAM}^{10}$. Two domains represent the FIM $^{\text {TM }}+$ FAM namely the motor domain with 17 items (FIM) and the cognitive domain with 15 items (FAM). The scale consists of seven categories ( $I=$ lowest and 7 highest score) which measure the independence of a person in daily life activities such as Physical, Psychosocial, Communication and Extended Activities of Everyday Living. It reflects changes in behavior from dependence to independence. The FIM $^{\mathrm{TM}}+$ FAM is a measure of burden of care with higher end of the scale (I-7) indicating increased levels of independence $^{11,12}$.

The positive aspects of the FIM $^{\mathrm{TM}}+\mathrm{FAM}$ in the research environment are its ability to be used by the MDT across differing diagnoses. However, health care professionals have frequently voiced concerns, among colleagues anecdotally, that progress of the patients' recovery as observed clinically, is not translated to a numerical change on the FIM $^{\text {TM }}+$ FAM. This then has led the authors to look for an alternative outcome measure that would be more responsive to changes in TBI patients during the acute phase of rehabilitation.

The decision was made to consider a South African developed outcome measure, the Activity Participation Outcome Measure $(\mathrm{APOM})^{13}$. The APOM measures eight domains: Process Skills (8 items), Communication and Interaction Skills (I0 items), Life skills ( 3 items), Role Performance (4 items), Balanced Lifestyle (3 items), Motivation (5 items), Self-esteem ( 7 items) and Affect ( 3 items). The scale has 18 categories and is based on the first six levels of creative ability as described in the Vona du Toit Model of Creative Ability (VdTMoCA $)^{14}$. The APOM is only accessible to occupational therapists with knowledge of the VdTMoCA and who are eligible to use the APOM after a one-day training workshop.

The APOM is yet to be used in the field of neurological rehabilitation. Volition in TBI patients plays an important role in their recovery process. The components of volition rely on various brain networks which may be broken down with disruption to any part of the network as seen in TBI. These networks underlie voluntary action and generate information for planning and controlling one's actions. Volition involves a sequence of decisions on whether to act, the type of action and when to perform it ${ }^{15}$.

The APOM is founded on the theoretical construct of Creative Ability namely volition and action ${ }^{13}$. This theoretic construct suggests that action is governed by motivation which is influenced by engagement in purposeful activity ${ }^{14}$. With this interaction, a person's motivation may increase when engaged in purposeful activity and increased motivation will likely lead to increased activity participation and thus makes the APOM an appropriate outcomes measure for TBI. The responsiveness to clinical change of this outcome measure with these TBI patients is however unknown.

The aim of this article is to report on the responsiveness of the APOM with TBI patients and compare it to an outcome measure, the FIM $^{\text {TM }}+$ FAM, that is currently used by occupational therapists in TBI populations in the country. The null hypothesis was that the APOM is not more responsive in measuring change in activity participation than the FIM $^{\mathrm{TM}}+\mathrm{FAM}$ during the acute phase of neurological rehabilitation in persons with TBI. Effect sizes from admission to discharge are also described.

\section{LITERATURE REVIEW}

$\mathrm{TBI}$ is an ongoing problem globally and in South Africa it appears to be increasing with high numbers of motor vehicle accidents, pedestrian accidents as well as violence related incidents ${ }^{16,17}$. The impact on occupational performance is significant, including loss of life roles and the subsequent financial implications for families and communities that may prevail over a lifespan ${ }^{18,19}$.

The scarcity of human and organisational resources in South Africa and the difficulty with accessing available resources, often leads to poor quality of life outcomes not only for the person who has suffered a TBI, but also their family ${ }^{17,20}$. It becomes imperative to provide early stage interventions that is appropriate and sustainable to meet the needs of the patient and family. One of the ways that sustainability can be achieved is through demonstrating change in outcomes during and after intervention to funders. Funding for rehabilitation comes from medical aids, workman's compensation (Commissioner for Occupational Injuries and Disease - COID) as well as self-funding.

Outcome measures that are routinely used in measuring outcomes in TBI include the Bartel Index, the FIM $^{\text {TM }}+$ FAM, Glasgow Outcome Scale as well as the Glasgow Outcome Scale - extended, Disability Rating Scale, Functional Status Examination and several quality of life measures such as WHO Quality of Life - BREF, European Quality Five Dimensions questionnaire, 36-item Short Form Survey, European Brain Injury Questionnaire ${ }^{18}$. Validity and reliability, including responsiveness have been demonstrated to a certain degree in these instruments but the heterogeneity of persons with TBI makes it impossible to have a perfect outcome measure that addresses the varied needs of this client population ${ }^{18}$. Selecting appropriate outcome measures for TBI is hindered by poor operational definitions of the items that are being measured, lack of sensitivity and responsiveness, low ceiling effects ${ }^{18,19}$ and lack of clinically meaningful items in the measure ${ }^{21}$. Nichol et al. ${ }^{18}$ highlight the timing of the use of outcomes measures as a limitation as some of the self-reported measures may not be reliable in the acute stage when cognitive impairments have not been stabilised. There is a debate about the use of the FIM $^{\text {TM }}+$ FAM as an outcome measure. Lungren-Nilsson et al. ${ }^{22}$ found that the seven-category 
scale when used with $\mathrm{TBI}$ and stroke patients was disordered for the motor items of the FIMTM but that all the motor items were ordered if the scale was collapsed to four categories. Yet a factor analysis done by Turner-Stokes and Siegert" ${ }^{\prime \prime}$ showed that the construct of the UK FIM ${ }^{\text {TM }}+$ FAM is best presented in four distinct dimensions namely Physical, Psychosocial, Communication and Extended Activities of Everyday Living. These domains may be summed for a composite score of functional independence.

Responsiveness yielded a high effect size (amount of change) of between 0.86 - I.29 indicating a stronger relationship ". Sensitivity of the FIM and FAM has been reported by van Baalen et $\mathrm{a}^{23}$ as acceptable but with an outpatient population. In spite of controversy about the summed score of the FIM $^{\mathrm{TM}}+\mathrm{FAM}$, it continues to be a widely used outcome measure in rehabilitation $10,12,18,19,24$.

The APOM was introduced in 2010 and is thus still a new outcome measure ${ }^{13}$. Studies to date, including mainly unpublished work in the form of masters dissertations were completed in mental health care facilities ${ }^{25-28}$. Validity and reliability of the APOM has however been reported through these studies. Good internal consistency with Cronbach alpha values above 0.8 was achieved as well as good content and construct validity ${ }^{13,29}$. Responsiveness (Cohens d effect size) of the APOM in a mixed mental health diagnostic group was reported by Carter ${ }^{26}$ as 1.262 and Silaule ${ }^{28}$ as I.195.

Although a number of outcome measures are available for the $\mathrm{TBI}$ population ${ }^{18}$, there is a scarcity of studies that report on the functional outcomes of TBI during the acute stage or hospitalised phase of rehabilitation in the last ten years.

\section{METHOD}

\section{Design}

The study used a quantitative, prospective, longitudinal cohort de$\operatorname{sign}^{30}$ that compared the responsiveness to change of the APOM and $\mathrm{FIM}^{\mathrm{TM}}+\mathrm{FAM}$ in measuring change in the independent participation in occupational performance of patients who have suffered a TBI.

The site of the research was a 50-bed private rehabilitation unit in KwaZulu-Natal.

\section{The sample}

All participants were required to be over the age of 18 years, as the APOM as well as the FIM $^{\text {TM }}+$ FAM have been developed for a population 18 years and older. Participants who presented with a $\mathrm{TBI}$ as diagnosed by the referring medical practitioner to the research site and admitted between I September 2013 and 30 September 2014 were included. The sample included both males and females diagnosed with a TBI irrespective of the mechanism of injury. Patients who were medically stable and had an uninterrupted rehabilitation stay were included in the study.

According to the Raosoft sample size calculator ${ }^{31}$, a power calculation determined that 28 patients were required for the study. The margin of error was set at $5 \%$ and the confidence level at $95 \%$. The population of TBls at the rehabilitation unit is approximately 30 per annum.

\section{Research procedure}

A total purposive sampling was used and those who consented and met the inclusion criteria were included in the study. Once patients were admitted to the unit, assessments were done routinely by the entire team. This included assessments by the physiotherapist, occupational therapist, speech therapist, social worker, dietician, psychologist, nursing staff and the medical doctor.
The assessments were conducted over a 72-hour period followed by an admissions report to the funder reporting on admission findings, short term and long term goals of intervention and requested length of stay in order to achieve those goals.

Once patients were admitted to the unit the FIM $^{\mathrm{TM}}+\mathrm{FAM}$ is routinely completed by all members of the rehabilitation team for each patient on admission, weekly and on discharge. All team members were trained in the use of the FIM $^{\mathrm{TM}}+\mathrm{FAM}$. The assessments were conducted over a 72-hour period followed by an admissions report to the funder reporting on admission findings, short term and long-term goals of intervention and requested length of stay, in order to achieve those goals. Assessment then continued weekly and on discharge.

For the purposes of this study, the APOM was added to the routine but completed only by trained occupational therapists. Scores for the items of the APOM and FIM $^{\text {TM }}+$ FAM were recorded on a weekly basis on an Excel spreadsheet.

\section{Data analysis}

Standardised response means (SRM) were calculated for each domain from the raw data of the two outcome measures to determine the effect size from baseline to final assessments. This was calculated using the baseline assessment in the first week of treatment and the final assessment in the last week of treatment. The mean change was then divided by the standard deviation of the total scores. Middel and Van Sonderen's ${ }^{32}$ cut off points were used for the magnitude of the change: trivial change as SRM $<0.20$; small change as $S R M \geq 0.2 \leq 0.50$; moderate change as $S R M 0.5<0.80$ and large change as $S R M \geq 0.80$.

To compare the responsiveness between the APOM and FIM $^{\mathrm{TM}}+\mathrm{FAM}$, the dependent $\mathrm{t}$-test for paired samples was done to test if the null hypothesis should be rejected. Pearson's correlation coefficient was calculated to determine if there was a correlation between the total scores of the two outcome measures.

\section{Ethical Consideration}

The study obtained ethical approval from the university of the Witwatersrand ethics committees (MI308I I). Approval was also granted by the national rehabilitation standards manager of the Health Care group. Written informed consent was obtained from all the participants or from the family when a patient was not well enough to sign consent. Anonymity was ensured by assigning a number to the patients' computerised hospital number instead of their names. A list of the participating patients and their corresponding research numbers was kept safely and securely by the first author.

\section{RESULTS}

\section{Demographics of the sample}

Of the 28 patients that were available for the study, the data from 24 were used. Three patients were excluded as they had not been treated by a therapist trained in the use of the APOM. The fourth patient not included, was medically unstable and had repeated discharges and readmissions from the acute hospital setting to the rehabilitation unit within the overall length of stay.

The average length of stay in the rehabilitation unit for patients with TBI in this study was 5I.9I days. The length of stays ranged from 9 to I 8 days with a large standard deviation of 29.6. One participant stayed for 118 days ( 17 weeks) and could be viewed as an outlier. The most frequent causes of injury in this sample were MVAs followed by falls. The distribution of the demographics is presented in Table I (on page 73). 
Table I. Demographics of the sample $(n=24)$

\begin{tabular}{|c|c|c|c|}
\hline & Male n(\%) & Female $n(\%)$ & Total \\
\hline Sample (n) & $17(70.8)$ & $7(29.2)$ & $24(100)$ \\
\hline \multicolumn{4}{|l|}{ Age groups } \\
\hline $18-30$ & $4(16.7)$ & $\mathrm{I}(4.2)$ & $5(20.8)$ \\
\hline $31-40$ & $3(12.5)$ & 0 & $3(12.5)$ \\
\hline $4 I-50$ & $3(12.5)$ & $2(8.3)$ & $5(20.8)$ \\
\hline $51-60$ & $4(16.7)$ & $2(8.3)$ & $6(25)$ \\
\hline $61-70$ & I (4.2) & $2(8.3)$ & $3(12.5)$ \\
\hline $7 I-80$ & $2(8.3)$ & 0 & $2(8.3)$ \\
\hline \multicolumn{4}{|l|}{ Mechanism of TBI } \\
\hline MVA (vehicle) & $8(33.3)$ & $2(8.3)$ & $10(4 \mid .7)$ \\
\hline MBA (motor bike) & $3(12.5)$ & 0 & $3(12.5)$ \\
\hline Assault & I (4.2) & 0 & $I(4.2)$ \\
\hline Falls & $3(12.5)$ & $4(16.7)$ & $7(29.2)$ \\
\hline Pedestrian & $2(8.3)$ & $\mathrm{I}(4.2)$ & $3(12.5)$ \\
\hline \multicolumn{4}{|l|}{ Length of stay } \\
\hline 3 weeks & $3(12.5)$ & $2(8.3)$ & $5(20.8)$ \\
\hline 6 weeks & $3(12.5)$ & I (4.I) & $4(16.7)$ \\
\hline 9 weeks & $5(20.8)$ & $2(8.3)$ & $7(29.2)$ \\
\hline 12 weeks & $6(25)$ & $I(4.2)$ & $7(29.2)$ \\
\hline 15 weeks & 0 & 0 & 0 \\
\hline 17 weeks & 0 & $I(4.2)$ & $I(4.2)$ \\
\hline $\begin{array}{l}\text { Mean LOS in days } \\
\text { (SD) }\end{array}$ & $\begin{array}{l}50.8 \\
(S D 27.6)\end{array}$ & $\begin{array}{l}54.6 \\
\text { (SD 36.5) }\end{array}$ & $\begin{array}{l}51.9(\mathrm{SD} \\
29.6)\end{array}$ \\
\hline
\end{tabular}

\section{Responsiveness of the APOM and FIM $^{\mathrm{TM}}+$ FAM}

The Standardised Response Means (SRMs) that were used to determine change in the eight domains of the APOM and the two domains of FIM $^{\mathrm{TM}}+$ FAM are presented in Figure I.

The APOM showed a slightly higher average change than the FIM $^{\mathrm{TM}}+\mathrm{FAM}$. The null hypothesis was that the APOM is not more responsive than the FIM $^{\mathrm{TM}}+\mathrm{FAM}$ in demonstrating change. Based on the results the null hypotheses was not rejected as the $\mathrm{p}$ - value of I.349 indicated no statistical difference between the responsiveness of the APOM and FIM $^{\text {TM }}+$ FAM based on total scores. The Pearson correlation coefficient between the total APOM scores and the total $\mathrm{FIM}^{\mathrm{TM}}+\mathrm{FAM}$ scores was also high at $\mathrm{r}=0.952$.

\section{Effect size}

The findings of this study showed that the changes (as measured by the SRM) were well above the cut off point for the large category of $\geq 0.833$. All eight domains of the APOM ranged between I.623 and 1.945. The motor and cognitive domains of the FIM $^{\mathrm{TM}}+$ FAM was $\mathrm{I} .790$ and I .456 respectively. According to Coster et al..$^{33}$ there is no gold standard for change after rehabilitation and that further investigation is needed to establish the ideal change in specific settings.

\section{DISCUSSION AND IMPLICATIONS}

Data were analysed from 24 of the 28 patients. This number was below the recommended size of 28 for a confidence level of $95 \%$. The confidence level dropped to $70 \%$ with a sample of 24 .

There were more males represented in the study than females. Only $30 \%$ of the sample were females. This is consistent with the findings of the IMPACT study where $23 \%$ of the sample was female ${ }^{34}$. The IMPACT study however found no statistical link between gender and a more favourable outcome. In the second

APOM and FIM+FAM Standardised response means of clients with TBI $(n=24)$

2,500

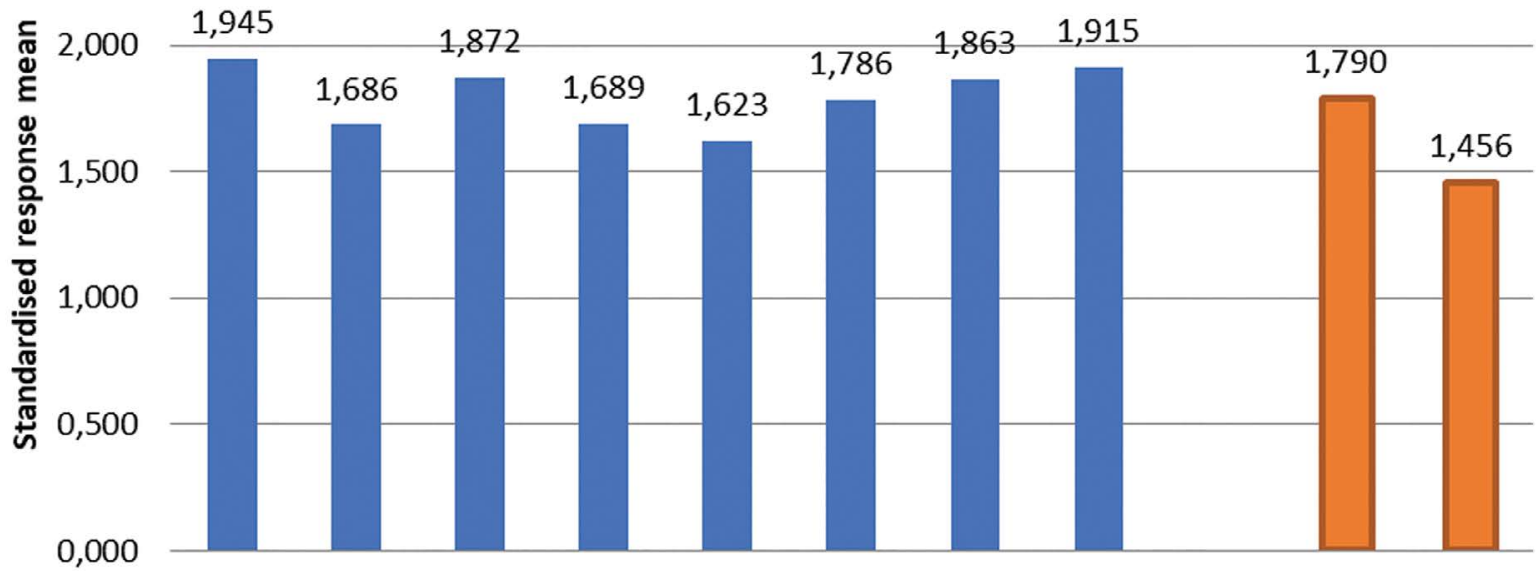

0,000

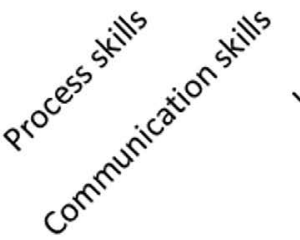

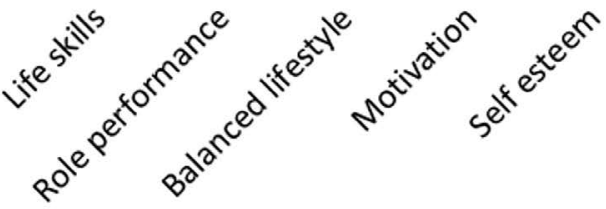

Domains of the APOM
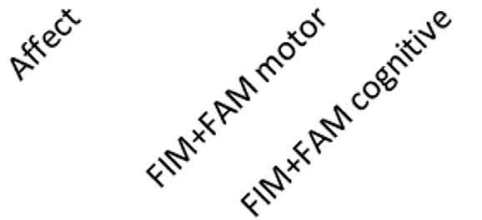

Domains of FIM+FAM

Figure I: Standardised response means of APOM and FIM ${ }^{\mathrm{TM}}+$ FAM of clients with TBI $(n=24)$ 
author's experience of I 7 years working with the TBI population, this trend of more males than females is a typical occurrence with $\mathrm{TBI}$ injuries.

The most frequent causes of injury in this sample were MVAs followed by falls. There was only one TBI as a result of assault which differs from the study performed at a public health care facility in the same city where assaults comprised the greatest mechanism of injury $^{16}$. However in the 2014 study at a public health care facility in another province in South Africa similar findings were found to this study, with MVAs being more common than assault ${ }^{35}$.

Although the APOM showed a larger SRM than the FIM $^{\text {TM }}+$ FAM (I.797 vs I.623), it was not statistically significant. This result was supported by a strong correlation (0.952) between the SRM of the APOM and the FIM $^{\text {TM }}+$ FAM. The positive implication about the results is that they could illustrate that the two measures have similar underlying constructs: activity participation and independent functioning and that these are highly correlated. This result could thus support concurrent validity of the APOM in TBI populations as the sequelae encompass all spheres of life. However, this should be investigated further with a larger sample.

The results of this study showed that Process Skills of the APOM $(S R M=1.945)$ had the biggest change followed by Affect (SRM $=1.915)$. On the FIM $^{\mathrm{TM}}+\mathrm{FAM}$, the cognitive domain showed the smallest change with a SRM of I.456. The cognitive domain of the FIM $^{\mathrm{TM}}+\mathrm{FAM}$ could be best compared with the domain of Process Skills in the APOM. Process Skills are the cognitive and executive functions that one uses to perform a task. This includes the ability to plan a task, select and use tools and materials appropriately, to pace the actions required and to adapt one's performance when problems are encountered ${ }^{13}$. Evidence from literature suggest problem solving, memory, managing stress and emotional outbursts to be the most common problems at one-year post injury 4 .

The domain of Affect showed the second biggest change. This domain incorporates repertoires of emotions, the control of emotions and mood $^{13}$. There are possible reasons for the marked change noted in these areas. There is evidence in the literature that the brain is spontaneously recovering after trauma. The state of internal chaos, as described by Winkler ${ }^{4}$, begins to settle with this spontaneous recovery in an ordered external environment and appropriate input by the MDT. Hence one would expect to see the measureable changes that were observed in this study, when using an outcome measure that is sufficiently responsive to demonstrate that change ${ }^{36}$.

Statistically, a good correlation between the total APOM and FIM $^{\text {TM }}+$ FAM scores was found. However, from a clinical point of view, the APOM provided greater insight into patients' activity participation in occupational performance capabilities than the FIM $^{\mathrm{TM}}$ FAM. The items of the domains provided a clearer picture in terms of Motivation, Affect, and Self-esteem. These are known areas of difficulty in the TBI population and were not identified in the FIM $^{\text {TM }}+$ FAM. The FIM $^{\text {TM }}+$ FAM on the other hand covered the motor aspects which the APOM did not cover. The Life skills domain area was of least clinical use in the APOM. It was unable to demonstrate the physical changes that occur on a participation level that the FIM $^{\text {TM }}+$ FAM could show. An example is with the FIM $^{\text {TM }}+$ FAM where self-care is divided into dressing, bathing, washing, grooming while the APOM has one item namely personal care and hygiene in the Life skills domain covering all aspects of self-care.

While statistically there was no difference in the responsiveness of the two outcome measures studied, the APOM was more useful to track changes on a weekly basis. The scale of the APOM is based on the levels of creative ability, where each level is subdivided into phases ${ }^{13,14}$. These phases are described as a progression from therapist directed, to patient directed and then into a transitional stage to the next level. When a patient was thought to be stagnating in their progress, by reviewing at what phase they were on in each level, this helped the therapists to demonstrate change to the funders descriptively in their weekly reports. Casteleijn ${ }^{29}$ investigated the validity of these levels and the phases within each levels to determine if they indeed represent increasing amounts of ability and found that the scale follows a linear or hierarchical pattern. Threshold ordering of the Rasch analysis was used and supported the validity of the levels.

In answering the question as to whether the APOM could be used by occupational therapists in a MDT environment where its underlying theoretical tenets are not known or understood by other disciplines of the team, this study has shown that the APOM can be used successfully by occupational therapists when reporting change to the team. Information gathered from other team members can help the occupational therapist determine what level of creative ability the patient should be at. Although team members may not use the APOM or fully understand the clinical implication of each level, the descriptors in the APOM are self-explanatory which any team member can understand. A report with these descriptors is generated for each patient and accessible to other team members. In addition, feedback in occupational performance as described by the APOM can be shared with team members in order for them to assist with setting discipline specific goals.

Patients with TBI in the acute stage display a wide variety of impairments and there is little heterogeneity amongst them. For this reason the APOM would be of better use for those patients who are colloquially described as being 'walkie-talkies' ${ }^{37}$. These are the patients who are automatically walking and talking but cannot make decisions about their care, follow a routine, participate in basic problem solving, and display dysexecutive functioning. Their activity participation is low, and they are often deceptive in their presentation. Families and therapists initially think that they are at a higher level of functioning than they actually are. The APOM with its underlying theoretical principles of the VdTMoCA is able to describe and quantify the levels of motivation and subsequent action. This will give a clearer picture of those kinds of patients and help to quantify their true level of activity participation in occupational performance. This is not able to be achieved as successfully with the $\mathrm{FIM}^{\mathrm{TM}}+\mathrm{FAM}$, as the patients will have high ratings for the physical components and communicative scores. Their overall rating will indicate that they are functional but will not show the significance of their cognitive impairment on occupational performance.

To illustrate this, one can take a task of dressing the upper body. A patient with a TBI scores at maximum assist (score of 2) on the FIM $^{\mathrm{TM}}+\mathrm{FAM}$ despite having the physical capability to perform the task. There are no difficulties on the impairment level such as with range of motion, muscle strength or motor planning. The occupational therapist determines that the patient has a low level of motivation which is the underlying cause of the low score on the FIM $^{\mathrm{TM}}+$ FAM. There is no category for motivation on the FIM $^{\mathrm{TM}}+\mathrm{FAM}$, thus the therapist writes about this in the descriptive report as being a problem. It would be of great benefit to the patient and the funder if the therapist each week could give a valid numerical score to the level of motivation that is affecting participation. In this way the funder could see that change was occurring that would have an ultimate effect on dressing upper body.

The APOM is a measure that has demonstrated its usefulness 
in capturing TBI patients' level of occupational functioning in the acute stages of neurological rehabilitation. In addition, it helped in goal setting and qualifying at what stage of participation the patient was, whether they were taking greater responsibility for an action or still requiring therapist direction for the task.

Use of more than one outcome measure is not justified financially in the acute rehabilitation setting of TBls. The lack of a measure of physical components in the APOM makes it a difficult measure to be the only one to use in an environment where there is a high physical burden of care in patients. However, it could be used in an environment where the physical impairments of a patient are quantified using impairment-based scales such as the Berg Balance, Modified Ashworth Scale for Spasticity, and Timed Up and Go Walking test. The value of the APOM would be that it could give a holistic picture of functioning that the occupational therapist could score with supplemental information from the rest of the team. The impairment-based scales require no license in order to use, thus there are no additional costs incurred beyond the monthly administrative fee of use of the APOM.

A limitation of the study was the small sample size and therefore the significance of the result should be interpreted with caution. The study was constrained by a self-imposed time limit of 12 months for data collection. In addition, there were only two trained occupational therapists in the unit that could utilise the APOM with their patients.

Occupational therapists trained in the VdTMoCA are invited to use the APOM to track change in their patients with TBI and to build the evidence of change that could be expected in this population.

\section{CONCLUSION}

This study added evidence of outcomes in a small TBI sample by comparing a specific occupational therapy outcome measure (APOM) with a generic one (FIM $\left.{ }^{\mathrm{TM}}+\mathrm{FAM}\right)$. Both outcome measures showed good responsiveness and there was no statistical difference between the two. The study also revealed the change as expressed by the SRMs in activity participation and independent functioning for this sample.

There is however value for Occupational Therapists to use the APOM in addition to the FIMS. This value lies in the rich descriptive information that can be used in feedback to the team and the family as well as the measurement of the motivational component.

\section{Acknowledgments}

The second author is the developer of the APOM.

\section{REFERENCES}

I. Faul M, Xu L, Wald MM, Coronado VG. Traumatic Brain Injury in the United States: Emergency Department Visits, Hospitalizations and Deaths 2002-2006. Atlanta (GA): Centers for Disease Control and Prevention, National Center for Injury Prevention and Control; 2010.

2. Stocchetti N, Zanier ER. Chronic impact of traumatic brain injury on outcome and quality of life: A narrative review. Critical Care. 2016; 20:148.

https://doi.org//0.1 186/s 13054-016-1318-1

3. Sacks $O$. The man who mistook his wife for a hat: And other clinical tales, New York: Touchstone; 1998.

https://doi.org/10.1192/bjp.166.1.130

4. Winkler P. Traumatic Brain Injury. In: Umphred DBG, Lazaro R, Roller M. (ed). Umphred's Neurological Rehabilitation. 6th ed. Missouri: Elsevier Mosby; 2013: 753 - 790. https://doi.org/10.1016/b978-0-323-07586-2.00033-9

5. Hawthorne G, Gruen RL, Kaye AH. Traumatic brain injury and long-term quality of life: findings from an Australian study. Journal of Neurotrauma. 2009; 26:1623 - 1633. https://doi.org/10.1089/neu.2008-0735

6. Huebner RA, Johnson K, Bennett CM and Schneck C. Community participation and quality of life outcomes after adult traumatic brain injury. American Journal of Occupational Therapy. 2003; 57(2): 177 - 85. https://doi.org/10.5014/ajot.57.2.177

7. Teasdale TW, Engberg A. Subjective well-being and quality of life following traumatic brain injury in adults: A long-term population-based follow-up. Brain Injury. 2005; 19(I2): 104I - 8. https://doi.org/I0.1080/02699050500I 10397

8. Radomski MV. Traumatic Brain Injury. In: Radomski MV TLC (ed) Occupational Therapy for Physical Dysfunction. 6th ed. Philadelphia: Lippincott Williams \& Wilkins; 2008: 1043 - 1077.

9. Laver K, Lannin NA, Bragge P, Hunter P, Holland AE, Tavender E, et al. Organising health care services for people with an acquired brain injury: an overview of systematic reviews and randomised controlled trials. BMC Health Services Research. 2014; 14: 397. https://doi.org/10.1 186/1472-6963-14-397

10. Wright J. Introduction to the Functional Assessment Measure. The Centre of Outcome Measurement in Brain Injury 2000 [cited 2015 May 20]. Available from: http://www.tbims.org/combi/FAM.

II. Turner-Stokes L, Siegert RJ. A comprehensive psychometric evaluation of the UK FIM + FAM. Disability and Rehabilitation. 2013; 35(22): 1885 - 1895. https://doi.org//0.3109/09638288.2013.76627।

12. Hall KM, Hamilton B, Gordon W, Zasler ND. Characteristics and comparison of functional assessment indices: Disabiltiy Rating Scale, Functional Independence Measure and Functional Assessment Measure. Head Trauma Rehabilitation. 1993; 8: 60 - 74. https://doi.org/10.1097/00001 199-199308020-00008

13. Casteleijn JMF. Development of an outcome measure for Occupational Therapists in mental healthcare settings. Department of Occupational Therapy. University of Pretoria; 2010. http://hdl.handle.net/2263/28019

14. de Witt P. Creative ability - A model for individual and group occupational therapy for clients with psychosocial dysfuntion. In: Crouch RB, Alers VM. (eds). Occupational Therapy in Psychiatry and Mental Health. 5th ed. London: Whiley \& Blackwell; 2014.

15. Zhu J. Locating volition. Consciousness and Cognition. 2004; I3(2): 302 - 322. https://doi.org/10.1016/j.concog.2003.09.003

16. Kamalo $P$. Retrospective analysis of outcomes and prognostic factors in patients with traumatic brain injury in KwaZulu-Natal, South Africa: towards the development of a prognostic model. Nelson R. Mandela School of Medicine. Durban: University of KwaZulu-Natal; 2013.

17. Naidoo D. Traumatic brain injury: the South African landscape. South African Medical Journal. 2013; 103: 613 - 614. https://doi.org//0.7196/samj.7325

18. Nichol AD, Higgins AM, Gabbe BJ, Murray LJ, Cooper DJ, Cameron PA. Measuring functional and quality of life outcomes following major head injury: common scales and checklists. Injury. 20I I; 42: 281 - 287. https://doi.org/10.1016/j.injury.2010.11.047

19. Shukla D, Devi BI, Agrawal A. Outcome measures for traumatic brain injury. Clinical Neurology and Neurosurgery. 20 I I; I I 3: 435 - 44I. https://doi.org/10.1016/j.clineuro.2011.02.013

20. Saggie J. Trauma: South Africa's other epidemic. South African Medical Journal. 2013; 103; 589 - 590.

http://www.scielo.org.za/scielo.php?pid=S0256957420 130009000 02\&script $=$ sci_arttext\&tlng $=p t$ 
2I. Wilson FC, Wheatley-Smith L, Downes C. Analysis of intensive outpatient neuro-rehabilitation outcomes using FIM+FAMUK. NeuroRehabilitation. 200; 24: 377 - 382. https://content.iospress. com/articles/neurorehabilitation/nre00492

22. Lundgren Nilsson A. Characteristics of the functional independence measure in patients with neurological disorders. Measurement through Rasch analysis. Institute of Neuroscience and Physiology, Department of Clinical Neuroscience and Rehabilitation. University of Gothenburg; 2006.

23. van Baalen $B$, Odding $E$, van Woensel MP, van Kessel MA, Roebroeck ME, Stam HJ. Reliability and sensitivity to change of measurement instruments used in a traumatic brain injury population. Clinical Rehabilitation. 2006; 20: 686 - 700. https://doi.org/10.1191/0269215506cre982oa

24. Turner-Stokes $L$. Standardized outcome assessment in brain injury rehabilitation for younger adults. Disability and Rehabilitation. 2002; 24(7): 383 - 9. https://doi.org/10.1080/09638280I 101550

25. Brooke C. Reliability and Relevance of the Activity Participation Outcome Measure to a Forensic Population of Mental Health Care Users. Occupational Therapy Department. Johannesburg: University of the Witwatersrand; 2015. http://nrfnexus.nrf.ac.za/handle/20.500.1 1892//2988 I

26. Carter M. Analysis of Routine Outcome Measurement Data in Mental Health Occupational Therapy. Occupational Therapy Department Northampton: University of Northampton; 2013.

27. Pillay S. Responsiveness to Change and Convergent Validity of the Activity Participation Outcome Measure (APOM) in Adolescent Mental Health Care Users. Occupational Therapy. Johannesburg: University of the Witwatersrand; 2016. http://wiredspace.wits.ac.za/handle/ I0539/2 I3I I

28. Silaule O. Routine Measurement of Outcomes for Mental Health Care Users attending Occupational Therapy in an Acute Mental Health Care Unit within a Rural Context. Occupational Therapy. Johannesburg: University of the Witwatersrand; 2017. http://wiredspace.wits.ac.za/handle//0539/23305

29. Casteleijn D. Using measurement principles to confirm the levels of creative ability as described in the Vona du Toit model of creative ability. South African Journal of Occupational Therapy. 2014; 44: 14 - 19. http://www.scielo.org.za/scielo.php?script=sci_arttext\&p id $=$ S23 I 0-383320 I 4000100004

30. Kumar R. Research methodology a step-by-step guide for beginners: Sage Publications Ltd.; 201 I.

31. Raosoft I. Sample size calculator. 2004. [cited 2014 April 21] Available at: http://www.raosoft.com/samplesize.html

32. Middel B, van Sonderen E. Statistical significant change versus relevant or important change in (quasi) experimental design: some conceptual and methodological problems in estimating magnitude of intervention-related change in health services research. International Journal of Integrated Care. 2002; 2(4). https://doi.org/10.5334/ijic.65

33. Coster WJ, Haley SM, Jette AM. Measuring self-reported outcomes after discharge from inpatient rehabilitation settings. Journal of Rehabilitation Medicine. 2006; 38: 237 - 242. https://doi.org/10.1080/16501970600609774

34. Mushkudiani NA, Engel DC, Steyerberg EW, Butcher I, Lu J, Marmarou A, et al. Prognostic value of demographic characteristics in traumatic brain injury: results from the IMPACT study. Journal of Neurotrauma. 2007; 24: 259 - 269. https://doi.org//0.1089/neu.2006.0028

35. Sobuwa S, Hartzenberg HB, Geduld H, Uys C. Outcomes following prehospital airway management in severe traumatic brain injury. South African Medical Journal. 2013; 103: 75I - 753. https://doi.org//0.7196/samj.7035

36. Houlden H, Edwards M, McNeil J, Greenwood R. Use of the Barthel Index and the Functional Independence Measure during early inpatient rehabilitation after single incident brain injury. Clinical Rehabilitation. 2006; 20: 153 - 159. https://doi.org/10.1191/0269215506cr917oa

37. Festa, D. Through the eyes of the heart: Stories of Love and Loss. Eugene, OR (USA): Resource Publications; 2016.

\section{ROLE OF AUTHORS}

Alison Camp, the first author planned the study, obtained ethical clearance, did the data collection, data analysis and discussion. The study was conducted for an MSc research report. The first author assisted with the manuscript and added information of the data collection procedure and discussion.

Daleen Casteleijn, the first co-author was the supervisor of the MSc study, guided the student in planning the study, the data collection, data analysis and discussion. The co-author put together the first draft of the manuscript and guided the article writing process. Dineo Thupae, the second co-author assisted with the writing of the first draft of the manuscript, reviewed it for flow and consistency and submitted the manuscript for publication.

Corresponding Author

* Dineo Thupae

Email: dineo.thupae@wits.ac.za 